\title{
EADSG Guidelines: Insulin Storage and Optimisation of Injection Technique in Diabetes Management
}

\author{
Silver Bahendeka (D) - Ramaiya Kaushik - Andrew Babu Swai • \\ Fredrick Otieno · Sarita Bajaj · Sanjay Kalra • Charlotte M. Bavuma • \\ Claudine Karigire
}

Received: December 10, 2018 / Published online: February 27, 2019

(C) The Author(s) 2019

\section{ABSTRACT}

To date, insulin therapy remains the cornerstone of diabetes management; but the art of injecting insulin is still poorly understood in many health facilities. To address this gap, the Forum for Injection Technique and Therapy

Enhanced Digital Features To view enhanced digital features for this article go to https://doi.org/10.6084/ m9.figshare.7594157.

Electronic Supplementary Material The online version of this article (https://doi.org/10.1007/s13300019-0574-x) contains supplementary material, which is available to authorized users.

S. Bahendeka

Department of Internal Medicine, Mother Kevin Post Graduate Medical School, Uganda Martyrs University, Kampala, Uganda

S. Bahendeka $(\bowtie)$

St. Francis Hospital, Kampala, Uganda

e-mail: silverbahendeka@gmail.com

R. Kaushik

Shree Hindu Mandal Hospital, Dar es Salaam,

Tanzania

A. B. Swai

Muhimbili University College of Health Sciences,

Dar es Salaam, Tanzania

F. Otieno

Department of Clinical Medicine and Therapeutics School of Medicine, College of Health Science,

University of Nairobi, Nairobi, Kenya
Expert Recommendations (FITTER) published recommendations on injection technique after a workshop held in Rome, Italy in 2015. These recommendations are generally applicable to the majority of patients on insulin therapy, athough they do not explore alternative details that may be suitable for low- and middle-income countries. The East Africa Diabetes Study Group sought to address this gap, and furthermore to seek consensus on some of the contextual issues pertaining to insulin therapy within the East African region, specifically focusing on scarcity of resources and its adverse effect on the quality of care. A meeting of health care professionals, experts in diabetes management and patients using insulin, was

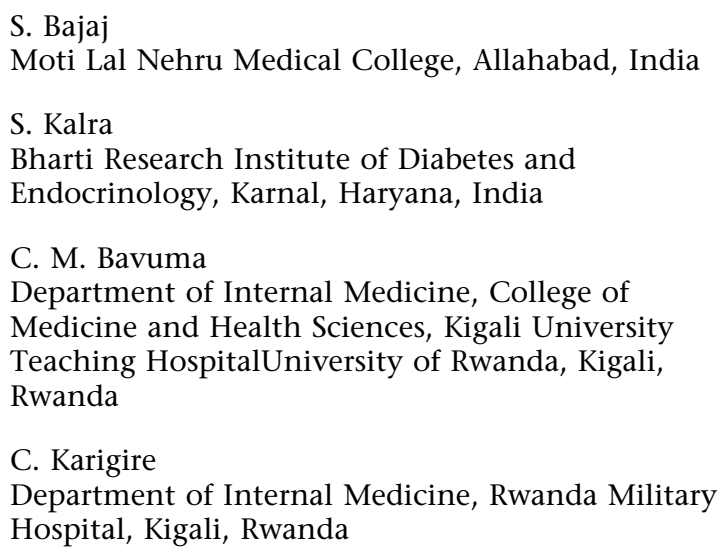


convened in Kigali, Rwanda on 11 March 2018, and the following recommendations were made: (1) insulin should be transported safely, without undue shaking and exposure to high $\left(>32^{\circ} \mathrm{C}\right)$ temperature environments. (2) Insulin should not be transported below $0{ }^{\circ} \mathrm{C}$. (3) If insulin is to be stored at home for over 2 months, it should be stored at the recommended temperature of $2-8{ }^{\circ}$. (4) Appropriate instructions should be given to patients while dispensing insulin. (5) Insulin in use should be kept at room temperature and should never be kept immersed under water. Immersing insulin under water after the vial has been pierced carries a high risk of contamination, leading to loss of potency and likelihood of causing injection abscesses. (6) The shortest available needles ( $4 \mathrm{~mm}$ for pen and $6 \mathrm{~mm}$ for insulin syringe) should be preferred for all patients. (7) In routine care, intramuscular injections should be avoided, especially with long-acting insulins, as it may result in severe hypoglycaemia. (8) The practice of slanting the needle excessively should be avoided as it results in sub-epidermal injection of insulin which leads to poor absorption and may cause "tattooing" of the skin and scarring. (9) In patients presenting in a wasted state, with "paperlike skin", injections should, if possible, be initiated with pen injection devices, so as to utilise the 4-mm needle without lifting a skin fold (pinching the skin); otherwise lifting of a skin fold is required, if longer needles are utilised. (10) Reuse of needles and syringes is not recommended. However, as the reuse of syringes and needles is practiced for various reasons, and by many patients, individuals should not be given alarming messages; and usage should be limited to discarding when injections become more painful; but at any rate not to exceed reusing a needle more than 5 times.

Keywords: Cold chain; Diabetes; Injection; Insulin; Low income

\section{INTRODUCTION}

Patients with type 1 diabetes (T1DM) require insulin therapy for their life time; and the majority of patients with type 2 diabetes
(T2DM) will require insulin therapy over time, due to the progressive decline in $\beta$-cell function [1]. The prevalence of known T1DM in East Africa is still low, but reported to be increasing; ranging between 4.8/100,000 and 16.4/100,000 in published studies [2]. The prevalence of T2DM in recent population studies in East Africa, has ranged from $1.4 \%$ to $12.0 \%$, with studies reporting over $50 \%$ previously undiagnosed cases of T2DM. Such patients are likely to present late with acute or long-term complications of T2DM and needing insulin therapy [3-9]. Therefore, within East Africa, there may be many patients requiring insulin therapy and assistance from health care providers in the management of the insulin therapy. In the absence of specific guidelines on insulin therapy for the region, the health care providers may not be in position to give detailed instructions to patients on proper injection techniques, and therefore there is an urgent need for guidelines on insulin storage and optimisation of injection technique in diabetes management, focusing on the East African region.

Until recently, many of the recommendations on insulin administration, globally, had little or no scientific underpinning and were based as much on habit and tradition as on evidence [1]. Moreover, the majority of patients with diabetes wish there were other ways of administering insulin, other than by injections, and are therefore not keen to learn about insulin therapy until insulin is prescribed. Therefore, improving patients' perceptions and acceptance of insulin should be a primary goal of diabetes care [10]. The importance of proper needle size, the correct injection process, complication avoidance and all aspects of injection technique from the first visit onwards should be addressed.

There are currently three classes of injectable medications available for diabetes therapy: insulin, glucagon-like protein 1 (GLP1) agents and amylin analogue [2-4]. These guidelines aim to complement previously published guidelines on insulin therapy [11] so as to optimise insulin therapy in diabetes management and will not discuss, in much detail, the administration of GLP-1 or amylin. These guidelines stress the need for correct technique 
in every insulin injection and show how critical this is for achieving optimal control of diabetes, noting that during the last few decades the recommended technique for insulin injection has changed [12]. The introduction of shorter needles $(4 \mathrm{~mm}$ for pen and $6 \mathrm{~mm}$ for insulin syringe) has led to the recommendation that the needle for administration of insulin should be inserted perpendicularly, without grasping a skin fold (pinching) [13]. Therefore, appropriate training of health care professionals is important so that instructions to the patients are adequately provided [10]. Table 1 summarises the recommended topics for diabetes educators regarding insulin injections.

Appropriate storage of insulin is necessary for preservation of insulin efficacy [14]. In all of Eastern Africa except the southern highlands of Tanzania and the northern part of the region (Sudan, Red Sea, Afar depression, northern Somalia), temperatures vary no more than $5{ }^{\circ} \mathrm{C}$; giving average room temperatures between $20-30{ }^{\circ} \mathrm{C}$ in most parts of the region [15]. Therefore, in the absence of reliable refrigeration in patients' homes in the majority of East Africa, it is prudent to recommend that within East Africa, insulin in use does not require refrigeration and should be kept at room temperature for a maximum of 6 weeks [16-18].

\section{METHODOLOGY}

A literature search on injection technique and preservation of insulin was done using Medline, PubMed and the Index African Health Journals Database by one of us (SB). The search was focused on the period between 2010 and 2018, and was restricted to full articles and the English language. MeSH terms injection, insulin, "insulin therapy", "subcutaneous injections", "injection technique", "insulin infusion", "insulin storage", "insulin transportation", "cold chain" and Africa were used. One of us (SB) summarised the literature review and drafted the initial version of the recommendations to guide the workshop on insulin therapy in Kigali, 11 March 2018. This workshop comprised of health care professionals (HCP), experts in diabetes care and patients on insulin therapy. The proceedings of
Table 1 A list of recommended topics for diabetes educators with regards to insulin injections. Adapted from Teaching injection technique to people with diabetes [19]

Recommended topics for diabetes educators

Education about injection technique for delivery of insulin, including a review of hypoglycaemia (causes, detection, treatment and prevention) as well as when to check blood glucose and individualised pre- and postmeal targets

Periodic review of injection technique and sites, especially when blood glucose control is suboptimal

Use, care and action of the medications(s) to be administered

Choice of injection devices, considering ease of use and patient limitations including cost, manual dexterity, hearing and visual impairment

For pre-filled devices, considering opened expiration date, total number of units/mg in device and daily dose when choosing devices, when applicable

Injection site selection and rotation, including teaching patient to examine sites for lipohypertrophy

Choice of needle: length and gauge to maximise comfort and efficiency

Technique

Timing of injection, related to the effect of the medication, meals, activity and stressors

Targets for dosing adjustments related to monitoring, activity stressors, and meals

Injection discomfort and complications

Safe disposal of used sharps

Quality control including medication storage considerations, opened and unopened expiration dates

Inspection of the injectable medication before each use

this workshop informed the final recommendations and consensus guidelines presented in this paper. The full list of attendees of this workshop is provided at the end of these guidelines. In drawing up the East Africa Diabetes Study Group (EADSG) guidelines: insulin storage and optimisation of injection technique in diabetes management, 
the authors adhered to the international and ethical standards in compliance with the Uganda National Council of Science and Technology (UNCST) for developing clinical practice guidelines (CPG) [20-22]. The hierarchical system of classifying the evidence is used in these guidelines and has been previously published [11]. The system classifies quality of evidence (as reflected in confidence in estimates of effects) as high (Grade A) and therefore highly recommended for adoption, moderate (Grade B), or low (Grade $\mathrm{C}$ ) according to factors that include the risk of bias, precision of estimates, the consistency of the results, and directness of the evidence; and consensus of expert opinion (Grade D) where there is hardly any published literature but consensus of expert opinion, to guide best treatement options in clinical practice. These guidelines are based on previously conducted studies and do not contain any studies with human participants or animals performed by any of the authors. Where photographs have been taken and used for demonstration, written consent was obtained and the photograph anonymised. The authors adhered to the international and ethical standards in compliance with the Uganda National Council of Science and Technology (UNCST) for developing clinical practice guidelines (CPG).

\section{INSULIN TRANSPORTATION AND STORAGE}

\section{Manufacturer to Country's Main Storage Facility}

The cold chain process is used for maintaining medication such as insulin, vaccines, and biologicals within a recommended temperature range, mostly between 2 and $8{ }^{\circ} \mathrm{C}$ throughout the supply chain. Most insulin storage data comes from the manufacturers, with few independent studies. Temperatures outside the recommended range reduce the potency of biologicals, leading to lack of desired response. Therefore, a cold chain must be used while transporting insulin from the production facility to the distributor's storage facility. A temperature log should be used for the whole transport. At the receiving end, the temperature log should be inspected by the recipient of the insulin and confirm the insulin was received in "good cold" chain. The practice includes sending the temperature log back to the manafacturer to confirm receipt of the insulin that mantained the recommended cold chain [14]. In the event of a cold chain breach, medications must be discarded. This practice should be observed in all cases.

\section{Distribution to Health Care Facility}

In the transportation of insulin from distributor to health care facility, suitable rigid containers should be used to maintain the temperature between 2 and $8{ }^{\circ} \mathrm{C}$. Suitable cool boxes and gel packs should be used to maintain the recommended cold chain temperature. Insulin should not be transported in containers having temperatures below $2{ }^{\circ} \mathrm{C}$, or be exposed to temperatures above $32^{\circ} \mathrm{C}$. Nowadays, boxes with sensors and a temperature logger are available that can accurately record the temperature within the box, and this option should be considered whenever feasible [14].

\section{Recommendation}

- To transport insulin from distributor to health care facility, suitable rigid containers should be used to maintain the temperature between 2 and $8{ }^{\circ} \mathrm{C}$ and to reduce damage to medicines during transit. Grade $\mathbf{A}$ 


\section{Storage of Insulin at Community Health Care Facility}

The community health care facility should have a refrigerator to store insulin. Refrigerators should be placed at least at an arm's length away from the wall, and also with sufficient space in between them, in the case of multiple refrigerators and/or freezers, so as to increase the air circulation. These refrigerators must not be used to store food, blood, or milk. The refrigerator for insulin should be defrosted every 6-8 weeks if it is not self-defrosting. The refrigerator for insulin should also have an integral thermometer which should be calibrated at least annually to ensure the readings are accurate.

Upon arrival from the distributor, insulin should be transferred to the refrigerator immediately. The pharmacist/health care worker should know the recommended safe storage temperature for every medication dispensed. Insulin should be stored in a refrigerator between 2 and $8{ }^{\circ} \mathrm{C}$ and should never be kept in the freezer or placed directly on ice [23]. Figure 1 shows a common mistake of putting insulin directly on ice, usually during transportation. This should be avoided.

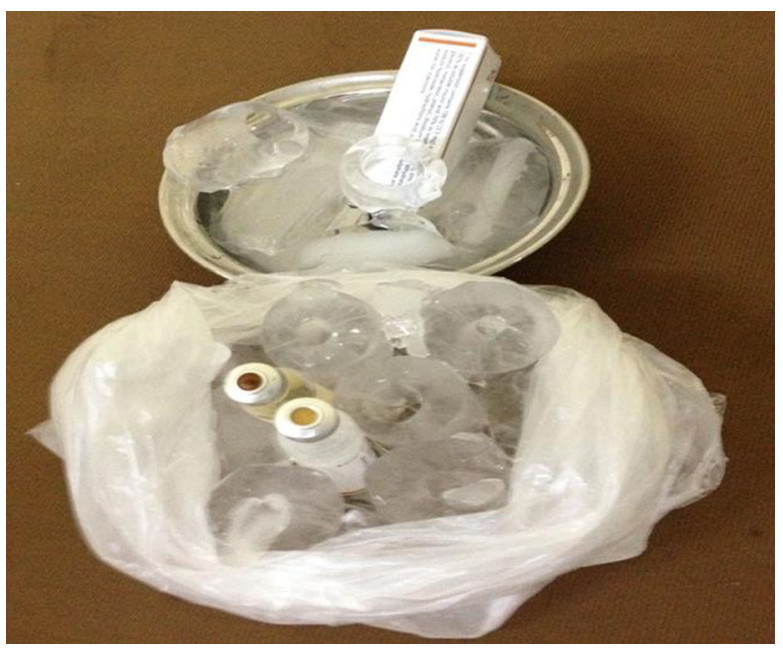

Fig. 1 This figure shows packaged insulin placed directly on ice cubes. In the top part, the insulin bottles are still in their cardboard box and in the lower one, the insulin bottles have been removed from the packaging. In both cases the method of keeping insulin cool is not recommended as it may result in the insulin freezing. Moreover, the melting water will destroy the labels on the insulin bottles

care facility to home in a plastic container. Insulin should remain in its initial packaging to protect it from sunlight. Insulin should not be

\section{Recommendation}

- Insulin at the community health care facility should be stored in a refrigerator that has a temperature monitor and the insulin should be kept between 2 and $8{ }^{\circ} \mathrm{C}$. Insulin should never be kept in the freezer or placed directly on ice. Grade A

\section{Transfer of Insulin from Pharmacy to Home}

Insulin needs to be dispensed with very clear instructions to the patient on how it should be transported home and subsequently used. Insulin should be transported from the health exposed to temperatures above $32^{\circ} \mathrm{C}$ because higher temperatures will reduce its potency [16-18]. Common examples of high temperatures in day-to-day life in East Africa, where temperatures may exceed $32^{\circ} \mathrm{C}$, include car glove boxes and the top of the engine next to the passenger seat in a minibus. 


\section{Recommendation}

Insulin should be dispensed with very clear instructions regarding its transportation from the health facility to the home and its safe storage and use at home; including recommendations on appropriate disposal of needles, syringes and other disposable materials. Grade A

An insulated bag or a cooling pouch is ideal for transportation of insulin to avoid sudden temperature variations [23]. A transport box can be improvised by using a plastic box as shown in Fig. 2. The common practice of placing insulin among ice cubes (as shown in Fig. 1); or strapping insulin directly on an ice pack is strongly discouraged as it may result in temperatures lower than the recommended $2{ }^{\circ} \mathrm{C}$. Transporting insulin immersed in water is equally discouraged, as it destroys the labels on the insulin vials. from sunlight, for 6 weeks, and 4 weeks if the temperature goes up to $30^{\circ} \mathrm{C}$, in a clean plastic box (Fig. 3). Storage at a higher temperature during use may degrade the insulin or convert it to higher molecular weight components [14]. Patients with diabetes need to be educated about temperature variations and duration of storage of insulin vials for maintaining the efficacy of insulin [19].

Keeping insulin in clay pots is likely to cause contamination as it is difficult to keep it clean: this should be avoided. Clay pots have been previously recommended [24].

\section{Recommendation}

- Store insulin in current use (pen, cartridge or vial) at room temperature (for a maximum of 6 weeks after initial use, and within the expiry date). Store unopened insulin in an area of the refrigerator where freezing is unlikely to occur. Grade B.

- If no refrigeration facilities are available in the home, it is recommended to liaise with the nearest health facility for the storage of the unopened insulin. Grade D.

\section{Storage of Insulin at Home}

Ideally, insulin should be stored in a refrigerator between 2 and $8{ }^{\circ} \mathrm{C}$ and also should be protected from light when vials or pens are unopened. The majority of families in East Africa do not have refrigeration facilities in their homes, and therefore other methods of safely storing insulin should be devised. Vials in use may be kept at room temperature $\left(20-25^{\circ} \mathrm{C}\right)$, protected

\section{BARRIERS TO INSULIN INJECTIONS}

The physician should involve the patient and, whenever possible, the family, when initiating insulin therapy; and a clear explanation given to the patient on the need for insulin therapy [25]. It must be noted that there are numerous myths associated with insulin injections among East African patients. The very words "needle" or "injection" carry complex 


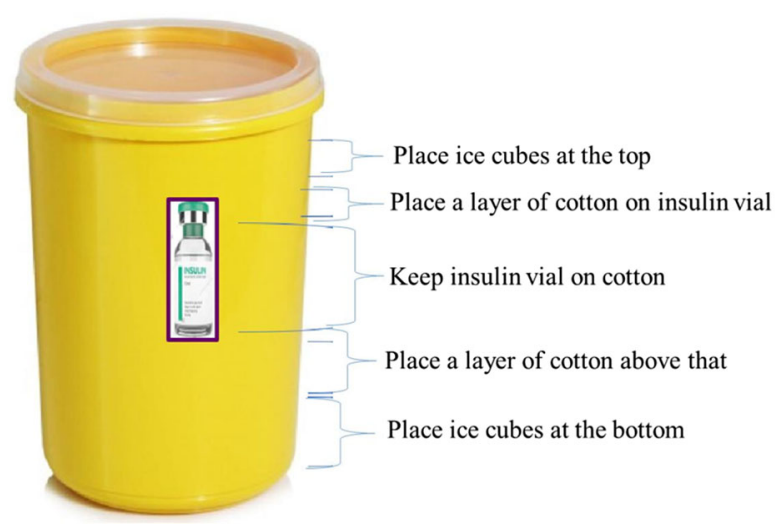

Fig. 2 Figure showing a suggested improvised box for the transportation of insulin from the health facility or pharmacy to home. The ice will keep the temperatures favourable for transportation even in the heat of the sun. Furthermore, the cotton layers ensure that the melting ice will not spoil the labels on the insulin, and also act as cushions against undue shaking of insulin during transportation

connotations. Sometimes, the suggestion of starting insulin could signify a message of failure of other therapies and that "drastic" measures are now needed. The common myths about insulin therapy in East Africa include:

- Insulin is started after all other therapies fail.

- Once on insulin treatment, it is always insulin treatment.

- Patients on insulin must eat before the insulin is injected, or else they pass out.

- Patients must always have a refrigerator at home to keep the insulin in.

- Insulin injections are always very painful.

- Injections are a social stigma.

- Starting insulin therapy means that the diabetes is severe and the patient has reached the end-stage (death is near).

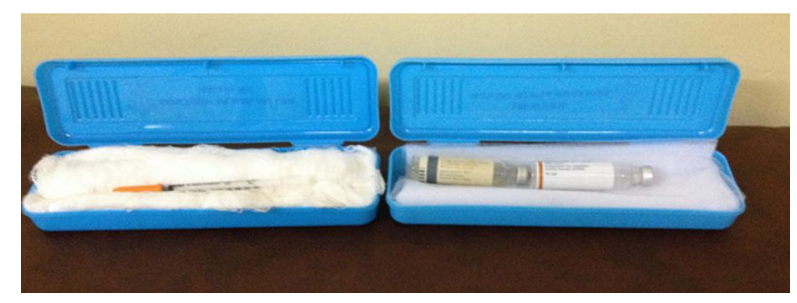

Fig. 3 Figure showing plastic containers with cotton. This is an improvised way of keeping insulin and syringes at room temperature $\left(20-30{ }^{\circ} \mathrm{C}\right)$. Insulin and syringes may be transported to work and to school in the same plastic containers

- Injection sites will soon become raw and exhausted.

- Insulin induces hypoglycaemia, a condition synonymous with death; and that this is almost always occurs in patients on insulin therapy.

Patients should be reassured and counselled about the safety of insulin therapy. They should be informed that initiating insulin therapy does not necessarily imply that the diabetes is in the last stage, and that well managed insulin therapy poses minimal complications. Patients with T2DM should be informed that insulin may be started right at the time of diagnosis, especially when metabolic control is poor and the blood glucose level is very high. They should also be told that, depending on the metabolic response, some patients may be shifted to oral hypoglycaemic agents after stabilisation of the metabolic state. Patients requiring long-term therapy with insulin should be informed accordingly and given the reasons why alternative medications are not applicable.

\section{Recommendation}

- The health care professional should inform all newly diagnosed patients with type 2 diabetes on likely future insulin therapy by explaining the natural, progressive nature of the disease, stating that it includes insulin therapy and making clear that insulin treatment is not a sign of patient failure. Grade C 


\section{Psychological Insulin Resistance}

Psychological insulin resistance is a term that physicians use to describe the psychological barriers against initiation and persistence with insulin therapy among patients. These barriers include cognitive, emotional, rational and cultural obstacles, but not psychological disorders. By preventing patients from starting and continuing to take the required insulin, psychological insulin resistance can lead to persistent hyperglycaemia and increased risks of developing complications. These barriers need to be identified and addressed [26].

\section{Overcoming Barriers for Insulin Injection}

Studies suggest that negative opinion about insulin therapy is modifiable. Barriers to insulin therapy are more of a temporary than a persistent phenomenon. There are many strategies physicians can use to overcome the barriers to insulin therapy, which include [27]:

- Referring patients for diabetes self-management education and medical nutrition therapy.

- Providing ongoing self-management support, and

- Addressing emotional issues.

The demonstration site should be similar to the sites of injection the patient is advised to use. Do not demonstrate on the leg, when the injection should be given on the thigh $[19,25-27]$.

\section{Therapeutic Education}

Therapeutic education is a process where the competencies (knowledge, skills and attitudes) and the necessary support for self-control of a disease are provided to the patient and his/her family and the competencies integrated into the treatment [28]. Traditionally, diabetes educators "instruct" patients and their relatives to follow the prescribed treatment. Such information is not sufficient to change their health behaviour. A patient's adherence depends on the learning strategies being used. In therapeutic education, patients acquire knowledge about their disease and the basis for treatment, so that they integrate knowledge and skills acquired into their daily lives to improve care and prevent acute and chronic complications. Therapeutic education for diabetes should accompany dispensing of insulin [28-30].

\section{The First Injection}

Around $40 \%$ of diabetes patients are scared of needle pain. Therefore, the first injection should be taken by the patient under the observation of a trained health care worker. The following steps help to overcome the fear [31]:

- The patient should be counselled and be informed that most people are afraid of the needle prick, until they do it and see how relatively pain-free it actually is.

- The sizes of the needles available should be demonstrated to reassure the patient that the needles are thin and short.

\section{INJECTION RECOMMENDATIONS}

Insulin is effective only if administered appropriately. Patient surveys demonstrate that patients continue to have many issues with insulin injection technique, highlighting the need for effective patient education [31].

\section{Site of Injection}

The four safe areas for insulin injections are the sides of the thighs, the backs of the upper arms, the abdomen and the upper outer buttocks. To avoid bumps and scar tissue on the skin, rotation of insulin injection sites should be done and a systematic approach to injection site rotation adopted.

Thus, injections may be given in the abdomen, outer thigh, back of the arm, and flank/ buttocks regions. The sites for rotation are shown pictorially in Fig. 4a, b. Insulin injected on the abdomen acts faster than insulin injected on the thigh. The rate of absorption of insulin injected on the arm is between that of insulin injected on the abdomen and that injected on the thigh [32]. 


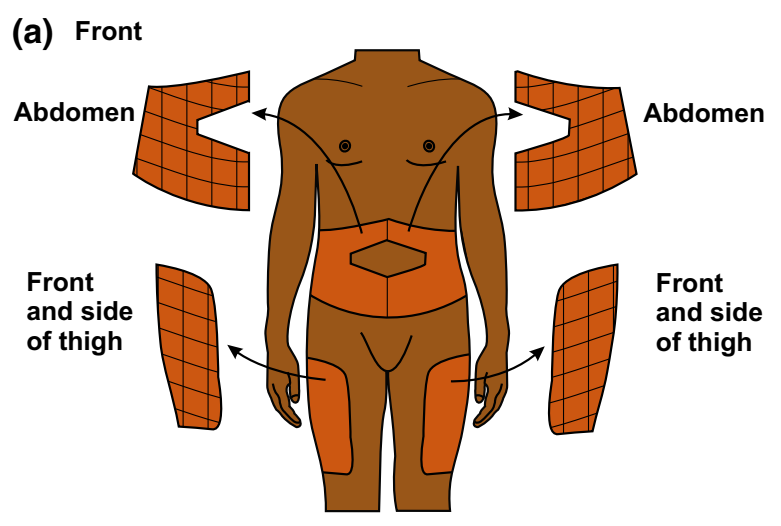

(b) Back

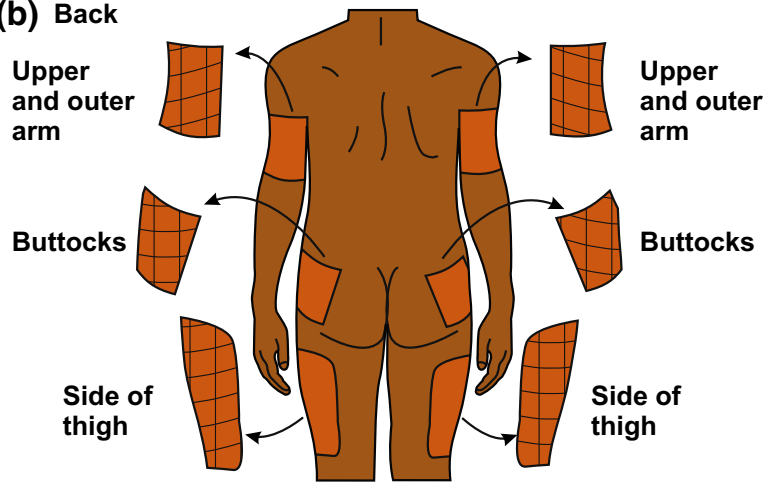

Fig. 4 a Figure showing the areas recommended for insulin injections as viewed from the front. They may be divided up into smaller areas, so that each area is injected not more than once a day. b Figure showing the areas recommended for insulin injections as viewed from the back

\section{Care of Injection Site}

The nature of the fat tissue under the skin changes with repeated injections into the same site and subsequently insulin is not appropriately absorbed. Proper care of injection sites should be taken to prevent complications [33]. Patients on insulin should be instructed to observe the following:

- To always visually inspect the injection sites before injecting insulin.

- To palpate the injection sites before injecting insulin. Patients should be instructed on how this is done.

- To avoid injecting into sites with lipohypertrophy, oedema, inflammation or signs of infection.
- To bathe with soap and water daily.

- To rotate sites of injection every day.

- Not to reuse the needle if possible; otherwise limit the reuse when injections become more painful; but should not reuse needles more than 5 times.

- There is no need to swab the area, if clean. If the injection site is not clean, clean with plain water. Swabbing with spirit-swabs is not recommended as it leaves the skin dry.

\section{Rotation of Sites}

Although insulin injections usually cause no significant pain, injecting at the same spot repeatedly can cause inflammation or fat tissue increase (lipohypertrophy), or scarring. Lipohypertrophy or scarring leads to poor insulin absorption and depot formation, which may affect insulin release, causing early postprandial hyperglycaemia and/or delayed hypoglycaemia. Therefore, rotation of injection sites is important to prevent lipohypertrophy and scarring, and thus improve the predictability of insulin absorption and action. Recommended ways of rotating injection sites are shown in Fig. 5. The same site should be used for at least 1 month and rotation should be done within the same site, rather than rotating to different sites with each injection. Each injection should be away from the previous one by a fingerbreadth $(2.5 \mathrm{~cm})$. Use of same site decreases variability

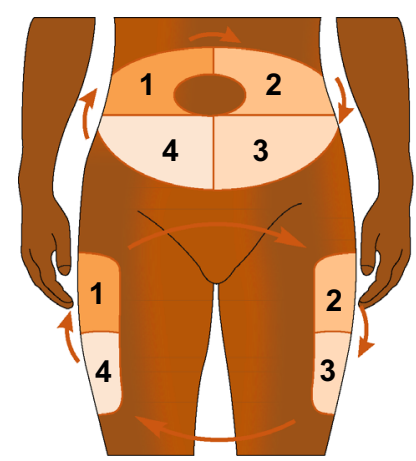

Fig. 5 Figure showing a method that can be adopted to rotate insulin injections. The recommendation is to rotate the injections within one site consistently. Here the figure shows the method of rotation on the abdomen in the upper part and the thighs in the lower part 
in day-to-day absorption of insulin. A site with open wounds or blisters should be avoided. Blood glucose monitoring should be done on change of site. Change of site of injection is frequently associated with hypoglycaemia [5].

For small children, it is good to use all the areas - arms, legs, abdomen and backside. Bigger children and teens should use the abdominal area most often.

\section{PHYSICAL ASPECTS OF INSULIN}

\section{Travelling with Insulin}

- Carrying insulin while travelling in hot climates can be a challenge. Insulin may be packed in a tight polythene bag and kept inside a small thermos flask [14].

\section{Precautions}

- Do not keep insulin in a locked car or in the glove compartment. Temperature in closed vehicles may reach very high levels (above $32{ }^{\circ} \mathrm{C}$ ), with loss of potency of insulin [14].

- When travelling by air, carry insulin supplies, along with a prescription, in cabin baggage or handbag. Luggage which is checked-in is stored in the aircraft's hold and may freeze: any insulin in this luggage may lose its potency [14].

- Do not store insulin near extreme heat (above $32^{\circ} \mathrm{C}$ ) or extreme cold sources (below $\left.2{ }^{\circ} \mathrm{C}\right)[14]$.

\section{Insulin in School}

Quality diabetes care at school is necessary for the child's immediate safety, long-term wellbeing, and optimal academic performance. To facilitate the appropriate care of the student with diabetes, the school teachers as well as other school personnel should understand diabetes and therefore need to be trained in its basic management, and the treatment of diabetes emergencies. The following should be addressed in the school [34]:
- Identify an appropriate location for insulin storage and follow the guidelines for insulin storage.

- Train one person from the school about insulin administration, doses/injection times prescribed for specific blood glucose values and for carbohydrate intake. The person should liaise with parent/guardian on insulin supplies and other essentials for diabetes care.

- Identify a location in the school to provide privacy during insulin administration, if desired by the student and family.

- The school authority should permit the student to check his or her blood glucose level and take appropriate action to treat hypoglycaemia or hyperglycaemia, when need arises.

- A school authority and preferably peers of the student to recognise symptoms of hypoglycaemia and hyperglycaemia and their immediate management.

- A school authority and preferably peers of the student to understand how participation in physical activity can be safely done.

- A school authority to receive instructions for handling diabetes emergencies.

- A school authority to have a plan for the disposal of sharps and other health waste.

\section{Insulin and Work}

- Insulin should be carried in a container to prevent exposure to extreme temperature and sunlight. If the work is in the field, the insulin should be placed in the shade where the temperatures are not high.

- The employer should provide a convenient place to store insulin and other supplies, if work conditions are not suitable for the temporary storage of insulin while at work, especially if the work place is not private enough to administer insulin.

- The employer should give permission to the employee to take short breaks to administer insulin as required. The employee should be permitted to consume food or beverages as needed at their desk or workstation, but this should conform to the social and cultural 
norms of the society, otherwise a convenient place should be identified for the patient to use $[28,35]$.

\section{Absorption of Insulin}

Multiple and varied factors affect insulin absorption. These are listed in Table 2. Patients should be told about these factors and be allowed to discuss factors that do affect the absorption of insulin. The abdominal site is the least susceptible to factors affecting insulin absorption. To minimise the variability of insulin absorption, patients should use one site of injection for a particular time consistently [33].

\section{Recommendation}

Recommendations on Pre-mixed human insulin

- In the morning, the regular/NPH mix should be given in the abdomen to increase the speed of absorption of the short-acting insulin in order to cover post-breakfast glycaemic excursions. Grade C

- In the evening, the regular/NPH should be given in the thigh or buttock as this leads to slower absorption and decreases the risk of nocturnal hypoglycaemia. Grade D

- Patients engaging in athletic activities after injecting pre-mixed human insulin should be warned about the occurrence of hypoglycaemia. Grade A

\section{Recommendation}

Recommendations on human long-and short acting insulin injections

- Intramuscular injection of NPH should be avoided since this may result in rapid absorption and consequent serious hypoglycaemia. Grade $\mathbf{A}$

- The thigh and buttocks are the preferred injection sites when using NPH as the basal insulin since absorption is slowest from these sites; if possible NPH should be given at bedtime rather than at dinner to reduce the risk of nocturnal hypoglycaemia. Grade B

- The abdomen is the preferred site for the soluble human insulin (regular), since absorption is fastest there. Grade B

- Patients engaging in athletic activities after injecting long- and shortacting human insulin should be warned about the occurrence of hypoglycaemia. Grade A 


\section{Recommendation}

Recommendations on Insulin analogues

- Rapid-acting insulin analogues may be given at any of the injection sites, as absorption rates do not appear to be site-specific. Grade B

- Rapid-acting analogues should not be given intramuscularly. Grade B

- IM injections of long-acting analogues should be avoided due to the risk severe hypoglycaemia. Grade A

- Patients engaging in athletic activities after injecting long-acting analogues should be warned about late onset occurrence of hypoglycaemia. Grade A

\section{ADMINISTRATION}

\section{Preparation of Skin for Injection}

Washing of hands with soap and water or with an antiseptic is required as a hygiene process. Hands should be dried before starting the process of injecting insulin [36, 37].

Swabbing of the injection site:

Swabbing of the skin with antiseptic is not necessary. Patients should keep clean all the time, and it is advised that they bathe daily. If the injection site seems dirty, cleaning of the skin with water should be done and thereafter dried with a clean towel. If an antiseptic cleansing agent is used, then the skin should be allowed to dry before injecting insulin [37].

\section{Injection Devices}

\section{Syringes and Vials}

Disposable plastic insulin syringes are the most widely used devices for insulin injection. Insulin syringes are available with $0.3-, 0.5-, 1-$, and 2-ml capacities.

- 0.3-ml insulin syringes are graduated in 1-unit intervals and are ideal for doses under 30 units because of their discrete size and easy 1-unit adjustment.

- $0.5-\mathrm{ml}$ insulin syringes are graduated in 1-unit intervals and are ideal for doses between 30 units and 50 units.

- 1-ml insulin syringes are graduated in 2-unit intervals and are ideal for doses over 50 units.

\section{Recommendation}

- Swabbing of the skin with an antiseptic is not required. If the skin appears dirty, use plain water and allow to dry before an injection is administered. Patients should bathe daily. Grade B 
Table 2 Factors affecting insulin absorption

\begin{tabular}{|c|c|}
\hline Factor & Effect on insulin absorption \\
\hline Exercise of injected area & $\begin{array}{l}\text { Strenuous exercise of a limb within } 1 \mathrm{~h} \text { of injection increases insulin absorption. For } \\
\text { example, injecting on the thigh and immediately riding a bicycle. This is clinically } \\
\text { significant for regular insulin and insulin analogues }\end{array}$ \\
\hline Local massage & Vigorously rubbing or massaging the injection site increases absorption \\
\hline Temperature & $\begin{array}{l}\text { Heat can increase absorption rate, including use of a sauna, shower, or hot bath soon } \\
\text { after injection. Exposure to a cold environment has the opposite effect }\end{array}$ \\
\hline Site of injection & $\begin{array}{l}\text { Insulin is absorbed faster from the abdomen. Less clinically relevant with long and } \\
\text { intermediate-acting insulins ( } \mathrm{NPH} \text {, insulin glargine and insulin detemir) }\end{array}$ \\
\hline Lipohypertrophy & Injection into hypertrophied areas delays insulin absorption \\
\hline Jet injectors & Increase absorption rate \\
\hline Insulin mixtures & $\begin{array}{l}\text { Absorption rates are unpredictable when suspension insulins are not mixed adequately } \\
\text { (i.e., they need to be re-suspended) }\end{array}$ \\
\hline Insulin dose & Larger doses delay insulin action and prolong duration \\
\hline $\begin{array}{l}\text { Physical status (regular versus } \\
\text { insulin suspension) }\end{array}$ & $\begin{array}{l}\text { Suspension insulins must be sufficiently re-suspended prior to injection to reduce } \\
\text { variability }\end{array}$ \\
\hline Insulin type & $\begin{array}{l}\text { Insulin aspart, glulisine and lispro appear to have less day-to-day variation in } \\
\text { absorption rates and also less absorption variation from the different body regions. } \\
\text { Insulin glargine's pharmacokinetic profile is similar after abdominal, deltoid or thigh } \\
\text { subcutaneous administration. More concentrated insulin has less variability (see } \\
\text { U200 and U500 insulins) }\end{array}$ \\
\hline
\end{tabular}

Length and thickness of needles have been reduced to minimise the pain during the injection, and to prevent inadvertent intramuscular administration of insulin. In the past few years, insulin needles were quite long $(12.7 \mathrm{~mm})$; these are no longer recommended. Shorter needles of 8-mm and 6-mm length were developed to reduce the pain, and avoid inadvertent intramuscular injection of insulin. Currently a 4-mm needle is available for pens and a 6-mm needle is available for syringes: these are suitable for all people with no pinching. Pinching may be necessary for some individuals with thin skin when using the $6-\mathrm{mm}$ or larger needles.

In East Africa, the conventional insulin and syringe are the most commonly used, while a few patients use pen devices. The cost of pen injection devices is a barrier to their use in East Africa.
Insulin injection using vial and syringe has the potential for several problems [38]:

- Inconvenience of carrying several materials.

- Preparing the syringe.

- Adverse psychological and social impact of using a syringe (syringes are associated with sickness and drug abuse).

- Use of an incorrect insulin product.

- Failure to administer accurate doses.

Insulin Pen Devices The first insulin pens were introduced in 1985, but they required loading. Loading was eliminated in 1989 with the development of the first fully disposable prefilled insulin pen. It was developed to improve treatment compliance. Pens are simple to use; and patient preference and satisfaction with insulin pens may lead to better adherence and thus better glycaemic control, which leads to reduced health costs. Insulin pens are 
significantly less painful and the scale is easier to read compared to the conventional vial/ syringe.

There are two types of insulin pen devices:

- Disposable or prefilled insulin pens: these devices come with insulin.

- Reusable insulin pens.

Insulin pens may be beneficial in difficult-totreat patient populations such as elderly individuals, patients with visual or dexterity impairments, children, and insulin-naive patients. The benefits of prefilled disposable pens have been established in a number of studies [39].

Limitations of insulin pens include higher prescription cost and inability for patients to mix their own insulin formulations [38].

Pen Needles Pen needles are available in different lengths: 4, 5, 6, 8, and $12.7 \mathrm{~mm}$. Shorter and thinner needles cause less pain; thinner needles cause less penetration force; while the five-grind needle tip needles cause less penetration force [38-43].

Pen needles with additional features to prevent injuries have been developed [42].

\section{Needle Reuse}

Ideally, disposable syringes and pen needles should be used only once. Reuse of syringes and needles may not guarantee sterility. Patients with poor personal hygiene, acute concurrent infections, open wounds on the hands, or decreased resistance to infection for any reason should not reuse a syringe or pen needle. The newer, smaller (30- and 31-gauge) needles have a thin tip. The needle tip can become bent to form a hook with single-use, which can lacerate tissue or break off to leave needle fragments within the skin. This may increase lipodystrophy or have other adverse effects [43].

Some patients reuse the needles for various reasons. Many patients find it burdensome to carry extra needles when away from home. They are also reluctant to carry containers to dispose of used needles. Others find that the injections from reused needles are not noticeably more painful. For reuse of a needle, it must be recapped after each use, and an inspection of the injection sites for redness or swelling must be done. A needle should be discarded if it is noticeably dull or deformed or if it has come

\section{Recommendation}

- A 4-mm needle is available for pens and a 6-mm needle is available for syringes; these are suitable for all people with no pinching. Pinching may be necessary for some individuals with thin skin when using the 6mm needles. Grade A

into contact with any surface other than skin $[29,41,44]$.

\section{Recommendation}

- Use a new sterile syringe and needle for every injection. Grade A

- While reusing needles is not recommended, the practice is common. Reuse should be restricted to a maximum of 5 times; fewer if the needle causes pain. Grade $\mathbf{C}$ 


\section{Disposal of Syringes}

Diabetes patients use various insulin pens, needles, syringes and lancets at home as a part of their self-care. Sharps, e.g. hypodermic, intravenous or other needles; auto-disable syringes; syringes with attached needles; infusion sets; scalpels; pipettes; knives and broken glass all contribute to the general sharps waste in the home, and should be disposed of safely.

Incorrect disposal of sharp objects among diabetes patients and members of their family can lead to needle-stick injuries among domestic waste handlers, and the community. The following have been identified as barriers for proper disposal of needles and syringes [42], and therefore should be addressed by health workers as part of diabetes care:

- Lack of information about how and where to dispose.

- Lack of proper advice by doctors and nurses.

- Wrong perception that sharps disposal information is meant only for illegal drug users,

- Some patients feel that using community sharps disposal services may result in revelation of their diabetes status, which may have been kept confidential.

- The perception that disposal of sharps into pit latrines or burning them in cooking fire stoves is a correct way of disposing of sharp hazardous waste, and cheaper.

It should be stressed to patients, their care givers and their families that home-generated hazardous waste resulting from syringes, insulin pens, gloves, blood glucose test strips and catheters used in day-to-day care needs to be disposed of safely. Sharps and, more specifically, needles, are considered to be the most hazardous category of healthcare waste for health care workers and the community at large, because of the risk of needle-stick injuries which carry a high potential for infection [45]. Waste should be segregated and disposed of safely. The correct segregation of health care waste is the responsibility of the health care provider and/or patient and care giver who produces each waste item. The simplest and safest waste segregation system is to separate all hazardous waste from non-hazardous general waste (which is generally of larger quantity) at the point of generation. The hazardous waste portion is very commonly separated into two parts: used sharps and potentially infectious items. Consequently, the segregation into separate containers of general non-hazardous waste, potentially infectious waste and used sharps is often referred to as the "three-bin system" [45]. Table 3 summarises the options for safe disposal of health care waste that may adopted by patients and their care givers.

Safe disposal of sharps used by patients with diabetes in different countries [45], showed that most of them followed either drop boxes, puncture-proof containers disposed of in the trash, and sharps container disposal at designated sites (Table 3). Studies on waste disposal in East African countries have highlighted challenges that range from lack of knowledge to lack of resources to implement good practices. There is therefore a need to identify cost-effective need-based solutions which are easily implementable as well as sustainable in East African countries [45].

\section{INJECTION TECHNIQUE RECOMMENDATIONS}

\section{Lifting Skin Folds (Pinching)}

When the local site for the injection is deemed clean, there is no need to prepare skin with alcohol or other antiseptic prior to lifting the skin fold and injecting the insulin [46]. Insulin should be injected and deposited into the subcutaneous space when prescribed as subcutaneous injection. Therefore, an appropriate needle size and length should be used. A 4-mm needle (pen device) or 6-mm needle and syringe is recommended. Lifting a skin fold (pinching) is done to avoid inadvertent intramuscular injection, and this should be done with $6-\mathrm{mm}$ or longer needles, especially in children and other patients with thin skin. The correct technique for lifting a skin fold (pinching) for injection should be taught to all patients. The lifted skin fold should be lifted up gently and not squeezed tightly to causes skin blanching or pain. Figure 6 shows a correctly lifted up (pinched) skin fold. 
Table 3 Guidelines for disposal of hazardous and non-hazardous waste

\begin{tabular}{|c|c|}
\hline Step & Guidelines \\
\hline \multirow[t]{5}{*}{$\begin{array}{l}\text { Collection of used needles and } \\
\text { syringes (sharp waste) }\end{array}$} & $\begin{array}{l}\text { Puncture-proof box with lid at the top to be used and labelled as "BIOHAZARD" } \\
\text { with a biohazard sign and yellow marked }\end{array}$ \\
\hline & Box should be filled up to $75 \%$ of its capacity only \\
\hline & $\begin{array}{l}\text { Recapping the needle, bending/cutting etc., and transfer of sharps using hands } \\
\text { should be avoided }\end{array}$ \\
\hline & $\begin{array}{l}\text { It is recommended that if possible, a needle cutter is used to cut needles off syringes; } \\
\text { and the needles then discarded into the sharp waste, while the plastic part of the } \\
\text { syringe is disposed of into a thick plastic bag (non-hazardous waste). Should a } \\
\text { needle cutter not be available and therefore the needle cannot be safely removed, } \\
\text { the whole syringe should be disposed of into the sharps box (hazardous waste) }\end{array}$ \\
\hline & $\begin{array}{l}\text { For picking up of needles or syringes, the syringe end should be preferred; if lying on } \\
\text { the ground, a long-handled tong should be used }\end{array}$ \\
\hline $\begin{array}{l}\text { Storage and disinfection in DICs } \\
\text { (hazardous -waste) }\end{array}$ & $\begin{array}{l}\text { Immersing the sharps in } 1 \% \text { sodium hypochlorite solution for } 30 \mathrm{~min} \text { and then } \\
\text { storing in a translucent white or blue coloured bin till final disposal from DIC }\end{array}$ \\
\hline \multirow[t]{2}{*}{$\begin{array}{l}\text { Final disposal from DIC (hazardous } \\
\text { waste) }\end{array}$} & $\begin{array}{l}\text { Link up with waste management agencies whenever possible; in case of non- } \\
\text { availability, an option of linking with a health facility having an incinerator should } \\
\text { be encouraged }\end{array}$ \\
\hline & $\begin{array}{l}\text { In the absence of the above possibilities, improvised local mechanisms of disposing } \\
\text { the hazardous waste in pits that are at least one metre in depth }\end{array}$ \\
\hline \multirow{3}{*}{$\begin{array}{l}\text { General health-care waste (non- } \\
\text { hazardous) }\end{array}$} & Colour of container usually black \\
\hline & Use a plastic bag inside a container which is disinfected after use \\
\hline & The bag should be filled to $75 \%$ only and collected at least once a day \\
\hline
\end{tabular}

DIC drop-in-centre

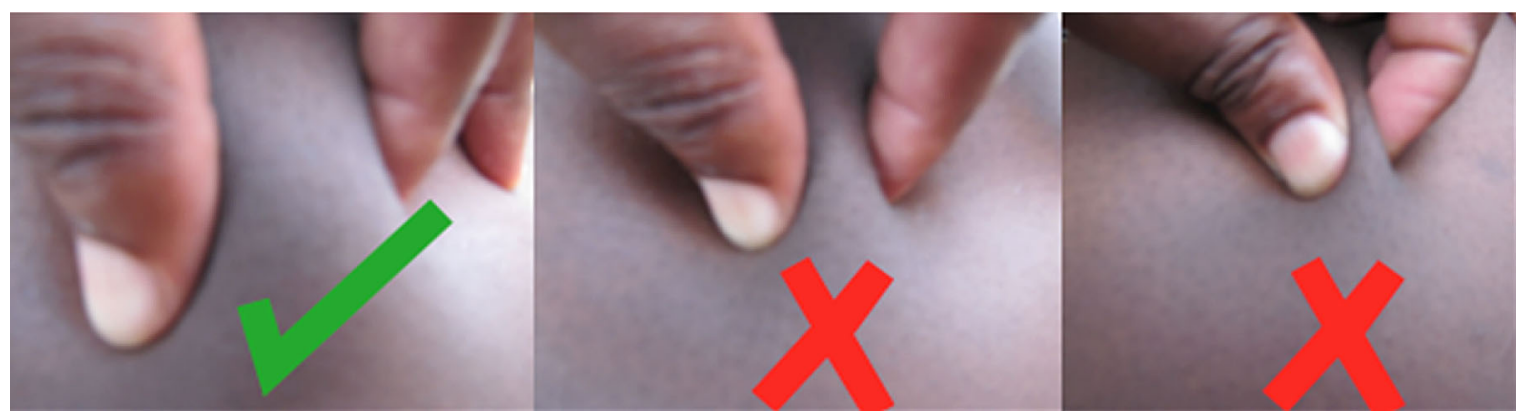

Fig. 6 The method of lifting up (pinching) a skin fold. The correct way is ticked with green; the wrong ways are crossed with red. Only moderate pressure should be exerted on the skin 


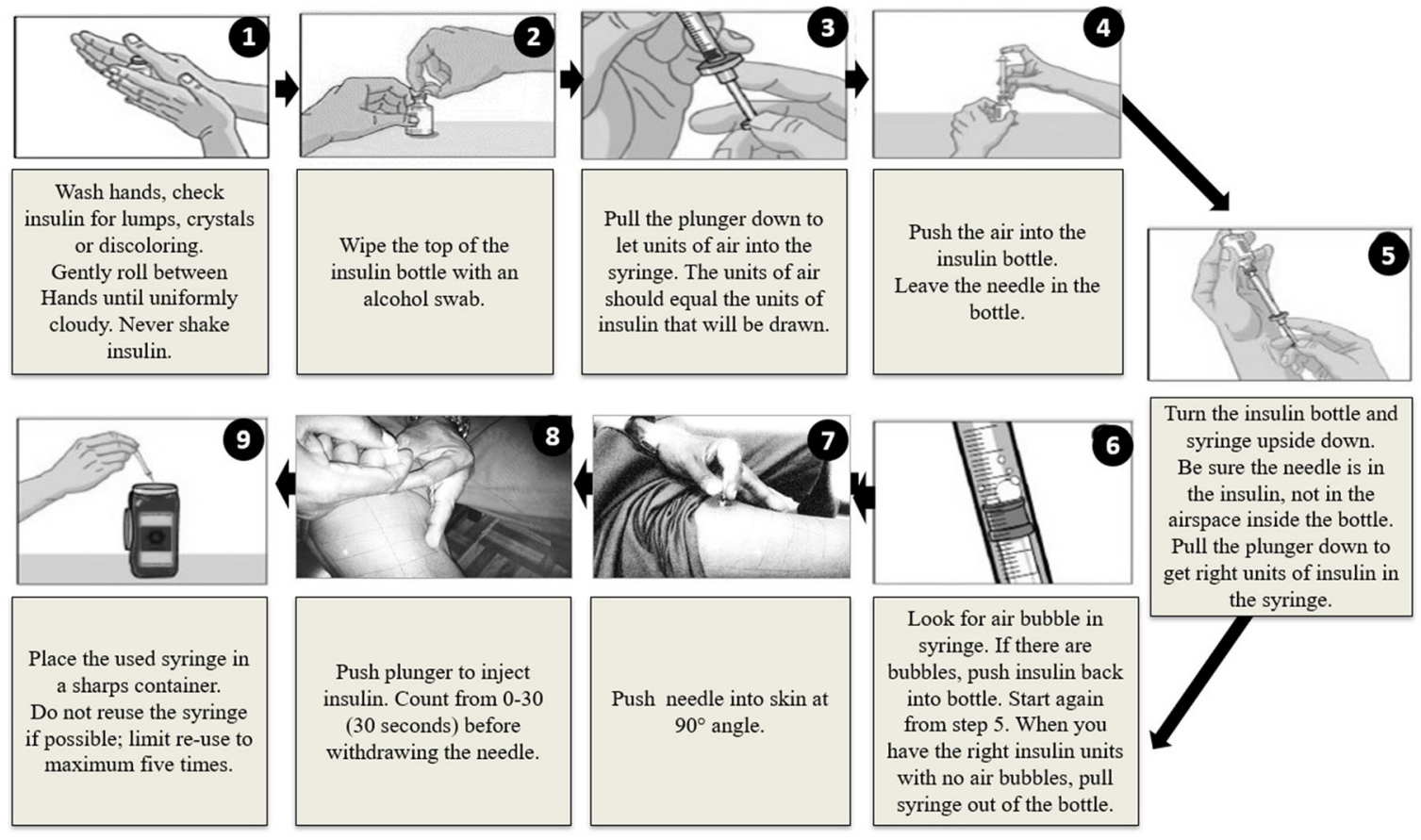

Fig. 7 This figure shows the steps that should be taken when insulin is injected. (1) Hands should be cleaned, and insulin gently mixed if it is the cloudy insulin. (2) The rubber on the bottle should be cleaned with spirit. If spirit is not available, cleaning should be done with water and the rubber dried with a tissue. (3) Air equivalent to the volume of insulin to be drawn, should first be drawn into the syringe, then injected into the bottle containing insulin. This is done to avoid creating a vacuum in the bottle containing insulin. (5) Insulin as required is then drawn into the syringe. (6) Ensure that the correct position

\section{The Proper Use of Syringes}

In East Africa, patients use syringes as their primary injecting device. It is recommended to use U-100 - 1.0-ml or 0.5-ml syringes. Careful attention should be paid to labels on the syringes when purchasing syringes, to ensure that correct syringes are purchased, especially if purchased from outside East Africa. There is no medical rationale for using syringes with detachable needles for insulin injection. Permanently attached needle syringes offer better dose accuracy and reduced dead space, allowing the patient to mix insulins if needed. There are currently no syringes with a needle less than of tilting insulin downwards is done, so to avoid drawing insufficient insulin. Insufficient insulin will be drawn if the bottle is not tilted appropriately and the needle sticks above the insulin level. Air bubbles should be removed. (7) The needle is pushed into the skin at $90^{\circ}$. (8) The plunger is advanced down and injection completed. It is recommended to allow the insulin injected to stabilise under the skin, by counting from 0 to 30. (9) The needle and syringe is removed from the skin and discarded into a plastic container, for appropriate disposal as hazardous waste

$6 \mathrm{~mm}$ in length, due to compatibility issues with insulin vial stoppers [42].

\section{Injection Technique for Syringe and Vials}

Insulin injection involves 2 steps: filling the syringe and injecting. The steps for injecting insulin are given pictorially in Fig. 7 [47].

\section{Injecting Insulin}

The following steps should be clearly elaborated to patients [48]:

- Choose where to give the injection. It may help to keep a chart of places used, so that 
insulin is not injected in the same place more than once in a day.

- Keep the injection $2.5 \mathrm{~cm}$ (one finger breadth) away from scars and $5 \mathrm{~cm}$ (two finger breadths) away from the umbilicus.

- Insulin should not be injected into skin that is bruised, swollen, or tender.

- The site chosen for the injection should be clean and dry. If the skin is visibly dirty, the area should be cleaned with plain water. Swabs containing spirit should not be used on injection sites; if used, the area should be left to dry prior to giving an injection of insulin. Patients are encouraged to bathe after work, and daily with soap and water to maintain good hygiene.

- If required lift (pinch) a skin fold and aim the needle perpendicularly at an angle of $90^{\circ}$. The procedure is the same whether a pen device or syringe is used to administer the insulin.
- If bleeding occurs, apply a cotton swab with some little pressure for $30 \mathrm{~s}$. This is usually sufficient. DO NOT RUB.

- Place the needle and syringe in a safe hard container. Close the container, and keep it safely away from children. This is the sharps waste container and the needles will be disposed of later appropriately. If the syringe and needle are to be reused, the needle should be carefully recapped, stored away in a clean container and reused later, but not more than 5 times.

- If more than 50 units of insulin is to be injected, it is advisable to split the doses and administer the divided doses either at different times or using different sites for the same injection. The health worker should be the one to determine the splitting of the doses. Large volumes of insulin are associated with more insulin absorption variability, which should be avoided.

Recommendations

Cloudy insulins

- Cloudy insulin (e.g. NPH and pre-mixed insulins) must be gently rolled and/or tipped (not shaken) for 20 cycles until the crystals go back into suspension (solution becomes milky white) before being injected. Grade A

- Push the needle into the skin. Let go of the pinched skin. Inject the insulin slowly and steadily until it is all in.

- Leave the syringe in place for 5-30 s after injecting; ensured by counting from 0 to 5 or up to 30. In East Africa we prefer to tell patients to count from zero to thirty as this is easily remembered.

- Pull the needle out at the same angle it went in. Put the syringe down.

- If insulin tends to leak from the injection site, put some pressure on the injection site with a piece of cotton swab for a few seconds: DO NOT RUB.

\section{SPECIAL SITUATIONS}

\section{Very Thin and Wasted Individuals}

For lean patients, it is recommended to use a 4-mm needle with a pen injection device, otherwise employ the combined use of a raised skin fold and angled insertion of the needle, if using needles longer than $4 \mathrm{~mm}[49,50]$.

\section{Very Obese Individuals}

Needle length should not be a concern in patients who are obese or overweight. In obese 
patients it still recommended to use 4- to 6-mm needles. Lifting a skin fold is not necessary in obese patients [49].

\section{Lipohypertrophy}

Lipohypertrophy is enlargement of adipocytes that manifests as swelling or induration of fat tissue, caused by insulin injection. Lipohypertrophy is seen in up to $50 \%$ of patients taking insulin [51].

Recommendations:

- Examine the sites for lipohypertrophy at least every 3 months, or more frequently. Injection sites should be gently palpated in order to feel the lipohypertrophy.

- Patients should be instructed on how to palpate the injection sites routinely; and on how to inspect their own sites. Patients should be given training in site rotation and proper injection technique.

- The size of the lipohypertrophy should be estimated by feeling its extreme edge and measuring its longitudinal and transverse diameters using a point $5-\mathrm{cm}$ (two finger breadth) away from the extreme edge of the lipohypertrophy. The site and the size of the lipohypertrophy should be documented in the patient's notes and referred to in future assessment of the lipohypertrophy.

- Patients should be requested to avoid injecting into areas of lipohypertrophy until the next examination. Recommend use of larger injection zones, correct injection site rotation, and non-reuse of needles.

- A reduced dose of insulin may be required after switching injections away from the lipohypertrophy, to avoid hypoglycaemia, as absorption of insulin will be better. Measure the blood glucose and adjust insulin dose.

\section{Pain}

Pain in injection therapy depends on the needle length and diameter, injection technique, and whether the injection is intramuscular [50]. Pain caused by intramuscular injections of insulin is described as stinging, and the pain is aggravated by contracting the muscle while the needle is in situ. Pain is also caused by reuse of a distorted or blunt needle. Use of short and narrow-gauge (4 to 5 $\mathrm{mm} \times 32 \mathrm{G}$ ) insulin pen needles reduces pain. Cold insulin is painful. The following measures assist in minimizing pain from insulin injections:

- Inject insulin that has a temperature of the surrounding room $\left(20-30{ }^{\circ} \mathrm{C}\right)$.

- Avoid the use topical alcohol for swabbing.

- Relax the muscles at the site during the process of injection.

- Quickly penetrate the skin.

- Do not change direction of the needle during insertion or withdrawal.

- Do not reuse needles, if possible.

- Do not use an injection device that puts pressure on the skin around the injection site.

- Apply a little pressure for 5 to $8 \mathrm{~s}$ after the injection, without rubbing: this is advised if an injection seems especially painful.

\section{PAEDIATRICS}

Diagnosis of diabetes in childhood causes stress and anxiety which hinders a parent's ability to administer insulin or encourage children to selfadminister insulin. Health care professionals should give appropriate education and demonstration of injection technique on themselves ("walking in the patient's shoes"): it helps parents, care givers, and children to overcome anxiety and other issues. Play therapy is a useful method of explaining injection technique. Injecting toys, dummies and "oranges" is strongly discouraged as it creates more fear and anxiety. All those present (physician, nurse, parents and relatives) should give the injection "without insulin" and appreciate "there is no pain" [51-53].

\section{Thickness of Subcutaneous Fat}

The thickness of skin and subcutaneous tissue varies from $4.9 \mathrm{~mm}$ in the arms of 2-6 year olds to $8 \mathrm{~mm}$ in $14-17$ year olds. The skin surface to muscle distance is $<4 \mathrm{~mm}$ in nearly 
$10 \%$ of children, especially in the 2 - to 6 -year age group. In this age group, the risk of intramuscular injections using the 4-mm pen needle, even when lifting a skin fold (pinching) is not done, is low (20.2\%). The $4-\mathrm{mm}$ pen needle should therefore be the recommended needle for all children. However, because the 4-mm needle is only available with pen devices, in East Africa it is recommended that a 6-mm needle and syringe be used along with appropriate lifting of a skin fold, to reduce the risk of intramuscular injection in children [51].

\section{Sites of Injection}

Insulin can be injected into the following areas in children:

- Outer arm.

- Abdomen.

- Hip.

- Thigh area.

For small children, it is good to use all areas - arms, legs, abdomen and the backside. In bigger children and adolescents, the abdomen may be used more often.

Choose the thighs or the buttocks for the evening NPH. This helps lower the chance of hypoglycaemia during the night.

Choose the abdominal area if exercise that will involve using the arms and legs is planned. Exercise can changes the dynamics of insulin action and should always be considered when insulin is being administered.

\section{Self-Injection}

There is no right age for the child to start injecting on his or her own. Some children may want to get used to having injections given to them by an adult, before learning to inject themselves. Studies have shown that children above 11 years can independently inject insulin. Children should not be excessively pressurised to administer their own injections. When they're ready, encourage them to self-inject. They should always be supervised [53].

\section{Needle Anxiety and Pain}

The fear of needles or needle phobia is common among children and adolescents. Consider intervention strategies for the parents to address needle anxiety and pain.

Recommendations

- Parents themselves have to be calm and composed before any injection. This is comforting for the child.

- Identify the past experiences with injections.

- Select appropriate syringes with needles attached or pens and 4-mm needles.

- Compare the needles used for other injections and insulin.

- Discuss how needles have been designed to improve patient comfort.

- Discuss alternative regimens to maintain adherence and reduce pain $[54,55]$.

\section{Insulin Underdosing and Overdosing}

Insulin under- and overdosing is an important area in patient care, but cannot be discussed in detail in these guidelines. Suffice to mention that when it is suspected, it requires specialised attention and care [56].

\section{PREGNANCY}

An optimal injecting technique during pregnancy has not established. However, the following recommendations are considered reasonable.

Recommendations:

- The abdomen is generally a safe site for insulin administration during pregnancy. However, as thinning of abdominal fat from uterine expansion is common, pregnant women with diabetes (of any type) should use a 4-mm pen needle when injecting on the abdomen. Other areas follow similar recommendations as in non-pregnant state.

- First trimester: hypoglycaemic events are most common during the 1st trimester. Close monitoring and dose adjustments are important. No change in insulin site or technique is needed. 
- Second trimester: insulin can be injected over the entire abdomen as long as properly raised skin folds are used. Lateral aspects of the abdomen can be used to inject insulin when no skin fold is raised.

- Third trimester: injections can be given into the lateral abdomen with properly raised skin folds. Apprehensive patients may use the thigh, upper arm, or buttock instead of the abdomen. Areas around the umbilicus should be avoided during the last trimester [32].

\section{ELDERLY}

Geriatric patients often have limited dexterity, visual impairment, and hearing impairment.

Recommendations [44]:

- Counsel elderly diabetes patients about the course of diabetes and proper injection technique.

- The elderly should be assisted by a care giver.

- Prevention and treatment of hypoglycaemia should be emphasised.

- Insulin pens are beneficial in the elderly due to their discreetness, simplicity, convenience of use and dosage accuracy.

- For visually impaired patients, the use of acoustic devices for glucose measurement is recommended.

- In patients with both visual and dexterity impairment, pre-filled syringes may be helpful.

- For patients with impaired hearing and those who use hearing aids, conduct education in a noise-free environment.

\section{HEALTH CARE RECOMMENDATIONS}

\section{Institutional Care}

In critically ill patients with hyperglycaemia, protocol-driven intravenous infusion is recommended. For achieving and maintaining glucose control in non-critically ill patients with diabetes or stress hyperglycaemia, scheduled subcutaneous insulin is recommended [57].

\section{Recommendations}

- The use of insulin pens instead of vial and syringes can provide several advantages for hospitalised patients, including greater satisfaction among them and health care providers, improved safety and reduced costs.

- Nurses need to follow the same principles of injection.

- Note that when insulin has to be injected intramuscularly, a needle for intramuscular injection fitted to a syringe that can adequately measure insulin dosage should be used. The usual $6-\mathrm{mm}$ needles or syringes will not deliver insulin intramuscularly [50].

\section{The Community}

Community nurses may have to give insulin injections to patients, if self-injection is not possible by the patient, or cannot be administered by a care giver. The community nurse should therefore be trained in insulin therapy, especially if involved in diabetes care [58].

Recommendations:

- A community nurse needs to learn how to administer insulin using both an insulin syringe and a pen device.

- Supplies of insulin syringes should always be available to community nurse teams.

- Review patients requiring insulin administration more than once a day to change to a once-daily regime wherever possible to reduce demand on the community team whilst maintaining appropriate glucose control and quality of life.

- It is recommended that a standard in-house protocol for community nursing teams to administer insulin be developed.

- It is recommended that such protocols should include the full name of the insulin, the dose to be given (with no abbreviation for the word 'units') and be signed and dated by the prescriber.

\section{DISCUSSION}

These are the first injection technique recommendations for East Africa, and they focus on 
needle length selection, the injection process and the choice of body sites. The recommendations also cover how insulin should be transported from the health facility to the patient's home and later how it should be stored at home. Additional recommendations have been provided on disposal of non-hazardous and hazardous (sharps) health waste; and the need to have national policies to cover these areas. Further recommendations have been provided on topics which, though addressed earlier, still lacked detail and specificity: lipohypertrophy, choice of needles in paediatric age groups, reuse of needles and patient education. These recommendations reflect our current synthesis of the available evidence, as well as expert consensus; we expect further changes following new research publications in this area, especially from the East African region.

Regardless of the patient group, the present recommendations guide the health worker and the patient towards using shorter $(4 \mathrm{~mm}$ with pens and $6 \mathrm{~mm}$ with syringe) needles. This appears to be the most efficient means of protecting against intramuscular injections in children and in those adults with "paper-thinskin" who are not able to appropriately lift skin folds (pinch). There is no medical rationale for the use of needles greater than $6 \mathrm{~mm}$ in children and adolescents, nor adults. The move to shorter needles is appropriate given the improved understanding of the anatomy of the skin and subcutaneous adipose tissue at the common injection sites, without an associated increase in cost of the syringes and needles. This change needs to be appreciated by government agencies, who procure the insulin syringes.

\section{BARRIERS TO ADOPTING THE RECOMMENDATIONS}

\section{Natural Resistance to Change}

Decisions imposed on people suddenly, with no time to get used to the idea or prepare for the consequences, are generally resisted. This natural resistance to change may be the first barrier to the implementation of these guidelines; for example, health workers and policy makers may request more time to transition from longer needles to shorter ones.

\section{Lack of Resources for Education}

Health facilities in East Africa do care for patients with diabetes, both type 1 and type 2 . However, only a few follow any specific guidelines, or have in-house protocols for managing diabetes [59-61]. Resources will therefore be required to mobilise the health care providers and educate them on the optimisation of insulin therapy and insulin injection technique. Patients with diabetes will also require a more detailed education on injection technique.

\section{Policy Change}

While the cost of smaller-sized needles is not different from that of longer ones which may be in current use in most health facilities [42], the change to smaller-sized needles implies a policy change that is a process. Keeping insulin and vaccines in the same refrigerator at the community health care facility may meet some resistance as it also requires a policy change.

\section{Consensus Statements and Lack of Evidence}

Consensus statements were produced because of lack of randomised controlled studies and other hard scientific data. These may meet challenges.

\section{Health Service Delivery}

Health service delivery in East Africa still has unmet needs for the management of diabetes. This impacts adversely on the choices of medical therapy and consequently on the quality of care. For example, the quantity of syringes supplied by the health authorities may not be sufficient and therefore must be reused if insulin has to be administered. Lack of trained health care providers in the field of diabetes leaves room for advice from non-qualified and untrained individuals. Such advice is likely not 
to be evidence based. Patients are frequently advised to slant the needle to almost being horizontal, leading to insulin being injected into the skin and causing scarring [11] or to transport insulin among ice cubes or in water.

Most patients requiring insulin therapy have to pay for some of the medications out of pocket [62], and this is a barrier to receiving quality care, as most have poor incomes.

\section{Strategy to Overcome the Barriers}

In order to ensure that the guidelines are adopted and implemented, it is of critical relevance to establish continuous education programmes for health workers and diabetes care givers. When recommending the guidelines, superior outcomes in diabetes care must be a key decision-making criterion. Studies examining outcomes in patients with diabetes in which these guidelines have been implemented should be encouraged and supported.

\section{ACKNOWLEDGEMENTS}

We wish to thank the patients who volunteered to have their photographs taken while giving an insulin injection.

Disclaimer. Springer Healthcare is not responsible for the validity of guidelines it publishes.

Funding. The East Africa Diabetes Study Group (EADSG) received an unrestricted study grant from Novo Nordisk towards the hosting of a workshop on insulin injections in Kigali, 11 March 2018. Novo Nordisk had no role in the design of these guidelines or their publication. No article processing charges were received by the journal for the publication of this article.

Editorial Assistance. Editorial assistance in the preparation of this article was provided by Dr. Punit Srivastava and Ms. Divya Sadhna of Mediception Science Pvt Ltd. This was funded by the EADSG.
Authorship. All named authors meet the International Committee of Medical Journal Editors (ICMJE) criteria for authorship for this article, take responsibility for the integrity of the work as a whole, and have given their approval for this version to be published.

Disclosures. Bahendeka Silver, Kaushik Ramaiya, Swai Babu Andrew, Otieno Fredrick, Sarita Bajaj, Sanjay Kalra, Bavuma Charlotte and Karigire Claudine have nothing to disclose.

Compliance with Ethics Guidelines. These guidelines are based on previously conducted studies and do not contain any studies with human participants or animals performed by any of the authors. Where photographs have been taken and used for demonstration, written consent was obtained and the photograph anonymised. In drawing up the East Africa Diabetes Study Group (EADSG) guidelines: insulin storage and optimisation of injection technique in diabetes management, the authors adhered to the international and ethical standards in compliance with the Uganda National Council of Science and Technology (UNCST) for developing clinical practice guidelines (CPG).

Open Access. This article is distributed under the terms of the Creative Commons Attribution-NonCommercial 4.0 International License (http://creativecommons.org/licenses/ by-nc/4.0/), which permits any noncommercial use, distribution, and reproduction in any medium, provided you give appropriate credit to the original author(s) and the source, provide a link to the Creative Commons license, and indicate if changes were made.

\section{REFERENCES}

1. Home P, Riddle M, Cefalu WT, et al. Insulin therapy in people with type 2 diabetes: opportunities and challenges? Diabetes Care. 2014;37(6):1499-508.

2. Marshall SL, Edidin D, Arena VC, Becker DJ, Bunker $\mathrm{CH}$, Gishoma C, et al. Prevalence and incidence of clinically recognized cases of type 1 diabetes in children and adolescents in Rwanda, Africa. Diabet Med. 2015;32(9):1186-92. 
3. Bahendeka S, Wesonga R, Mutungi G, Muwonge J, Neema S, Guwatudde D. Prevalence and correlates of diabetes mellitus in Uganda: a population-based national survey. Trop Med Int Health. 2016;21(3):405-16.

4. Ministry of Health, Kenya. STEPwise survey for noncomminicable diseases risk factors 2015 Report. 2015. http://www.who.int/ncds/surveillance/steps/ kenya/en/. Accessed 23 Dec 2017.

5. Ngwiri T, Were F, Predieri B, Ngugi P, Iughetti L. Glycemic control in Kenyan children and adolescents with type 1 diabetes mellitus. Int J Endocrinol. 2015;2015:761759.

6. McLarty D, Kitange HM, Mtinangi BL, Makene WJ, Swai ABM, Masuki G, et al. Prevalence of diabetes and impaired glucose tolerance in rural Tanzania. Lancet. 1989;333(8643):871-5.

7. Ministry of Health, Republic of Rwanda. Rwanda non-communicable diseases risk factors report. 2015. http://www.who.int/ncds/surveillance/steps/ rwanda/en/. . Accessed 23 Dec 2017.

8. International Diabetes Federation. IDF diabetes atlas. 8th ed. Brussels: International Diabetes Federation; 2017.

9. Amendezo E, Walker Timothy D, Karamuka V, Robinson B, Kavabushi P, Ntirenganya C, et al. Effects of a lifestyle education program on glycemic control among patients with diabetes at Kigali University Hospital, Rwanda: a randomized controlled trial. Diabetes Res Clin Pract. 2017;126:129-37.

10. Ellis K, Mulnier H, Forbes A. Perceptions of insulin use in type 2 diabetes in primary care: a thematic synthesis. BMC Fam Pract. 2018;19(1):70.

11. Bahendeka S, Ramaiya K, Andrew SB, Fredrick O, Bajaj S, Kalra S, Charlotte BM, Claudine K, Makhoba A. EADSG guidelines: insulin therapy in diabetes. Diabetes Ther. 2018;9(2):449-92.

12. Shah RB, Patel M, Maahs DM, Shah VN. Insulin delivery methods: past, present and future. Int J Pharm Investig. 2016;6(1):1-9.

13. Hirsch L, Byron K, Gibney M. Intramuscular risk at insulin injection sites-measurement of the distance from skin to muscle and rationale for shorter-length needles for subcutaneous insulin therapy. Diabetes Technol Ther. 2014;16(12):867-73.

14. Bhatnagar Arpit, Gupta Varun, Tandon Prashant, et al. Last mile delivery of cold chain medicineschallenges and recommendations. Indian J Pharm Biol Res. 2018;6(1):34-41.
15. Camberlin P: Climate of Eastern Africa. In: Oxford Research Encyclopedia, Climate SciencE (oxfordrecom/climatescience). edn.: Oxford University Press, USA; 2018: 1-52. http://oxfordre.com/clima tescience/view/2010.1093/acrefore/9780190228620. $9780190228001.9780190220001 /$ acrefore-9780190 228620-e-9780190228512? print=pdf. Accessed 02 Dec 2018.

16. Chandler C, Gryniewicz CM, Pringle T, Cunningham F. Insulin temperature and stability under simulated transit conditions. Am J Health Syst Pharm. 2008;65(10):953-63.

17. Vimalavathini R, Gitanjali B. Effect of temperature on the potency \& pharmacological action of insulin. Indian J Med Res. 2009;130:166-9.

18. Shnek DR, Hosteler DL, Bell MA, Olinger JM, Frank $\mathrm{BH}$. Physical stress testing of insulin suspensions and solutions. J Pharm Sci. 1998;87(11):1459-65.

19. American Association of Diabetes Educators. Teaching injection technique to people with diabetes. American Association of Diabetes Educators 2017. https://www.diabeteseducator.org/docs/defa ult-source/practice/practice-documents/practice-pa pers/teaching-injection-technique-to-people-withdiabetes.pdf?sfvrsn=0. Accessed 9 Jan 2018.

20. Hinson AM, Stack BC: Evidence-based medicine: approach and references classification. In: Medical and surgical treatment of parathyroid diseases. Edited by Stack BC, Bodenner DL; 2017. pp. 11-13.

21. Institute of Medicine (IOM). Clinical practice guidelines we can trust. Washington, DC: The National Academies Press; 2011.

22. Heneghan C, Badenoch D. Evidence-based medicine toolkit, second edition. Malden: Blackwell Publishing, Inc.; 2006.

23. Shafaat $\mathrm{K}$, Hussain A, Hussain $\mathrm{S}$, et al. An overview: storage of pharmaceutical products. World J Pharm Sci. 2013;2(5):2499-515.

24. Ogle GD, Abdullah M, Mason D, Januszewski AS, Besancon S. Insulin storage in hot climates without refrigeration: temperature reduction efficacy of clay pots and other techniques. Diabet Med. 2016;33(11):1544-53.

25. Funnell MM. Overcoming barriers to the initiation of insulin therapy. Clin Diabet. 2007;25(1):36-8.

26. Gulam AH, Otieno CFF, Omondi-Oyoo G. Prevalence of psychological insulin resistance among patients with type 2 diabetes at Kenyatta National Hospital, Kenya. Health Sci J. 2017;11:3. 
27. Bin Rsheed A, Chenoweth I. Barriers that practitioners face when initiating insulin therapy in general practice settings and how they can be overcome. World J Diabetes. 2017;8(1):28-39. https://doi.org/10.4239/wjd.v8.i1.28.

28. Therapeutic Patient Education. Continuing Education Programmes for Health Care Providers in the Field of Prevention of Chronic Diseases. Report of a WHO Working Group. WHO; 1998.

29. Jansà M, Vidal M. Therapeutic education in chronic patients: the diabetes model. Endocrinol Nutr. 2015;62(2):53-5.

30. Allen NA, Zagarins SE, Feinberg RG, Welch G. Treating psychological insulin resistance in type 2 diabetes. J Clin Transl Endocrinol. 2017;7:1-6.

31. Spollett G, Edelman SV, Mehner P, Walter C, Penfornis A. Improvement of insulin injection technique: examination of current issues and recommendations. Diabetes Educ. 2016;42(4):379-94.

32. Tandon N, Kalra S, Balhara YP, et al. Forum for injection technique (FIT), India: the Indian recommendations 2.0 , for best practice in insulin injection technique, 2015. Indian J Endocrinol Metab. 2015;19(3):317-31.

33. de Meijer PHEM, Lutterman JA, van Lier HJJ, van't Laar A. The variability of the absorption of subcutaneously injected insulin: effect of injection technique and relation with brittleness. Diabet Med. 1990;7(6):499-505. http://doi.org/10.1111/j.14645491.1990.tb01431.x.

34. American Diabetes Association. Diabetes care in the school and day care setting. Diabetes Care. 2009;32 (Suppl 1):S68-72. https://doi.org/10.2337/dc09-S068.

35. American Diabetes Association. Diabetes and employment. Diabetes Care. 2011;34(Suppl 1):S82-6. https://doi.org/10.2337/dc11-S082.

36. Donner T. Insulin-pharmacology, therapeutic regimens and principles of intensive insulin therapy. [Updated 2015 Oct 12]. In: De Groot LJ, Chrousos G, Dungan K, et al., editors. Endotext [Internet]. South Dartmouth (MA): MDText.com, Inc.; 2000. Available from: https://www.ncbi.nlm. nih.gov/books/NBK278938/table/insulin-pharmaco logy.factorcomm/. Accessed 23 Jan 2018.

37. Kansra UC, Sircar S. Insulin therapy: practical points. J Ind Acad Clin Med. 2000;1(3):285-92.

38. Selam J-L. Evolution of diabetes insulin delivery devices. J Diabetes Sci Technol. 2010;4(3):505-13.

39. Ramadan WH, Khreis NA, Kabbara WK. Simplicity, safety, and acceptability of insulin pen use versus the conventional vial/syringe device in patients with type 1 and type 2 diabetes mellitus in Lebanon. Patient Prefer Adher. 2015;9:517-28. https:// doi.org/10.2147/PPA.S78225.

40. Hirsch IB. Does size matter? Thoughts about insulin pen needles. Diabetes Technol Ther. 2012;14(12): 1081.

41. Aronson R, Gibney MA, Oza K, et al. Insulin pen needles: effects of extra-thin wall needle technology on preference, confidence, and other patient ratings. Clin Ther. 2013;35(7):923-33.

42. Beckton Dickinson: Out Products -BD- Beckton Dickinson. https://www.bd.com/en-uk/products. Accessed 20 Jan 2018.

43. Pearson TL. Practical aspects of insulin pen devices. J Diabetes Sci Technol. 2010;4(3):522-31.

44. American Diabetes Association. Insulin Administration. Diabetes care. 2003;26(suppl 1):s121-4.

45. World Health Organization. Safe management of wastes from health-care activities: a summary. Geneva: World Health Organizatio; 2017. (WHO/ FWC/WSH/17.05). Licence: CC BY-NC-SA 3.0 IGO.

46. Koivisto VA, Felig P. Is skin preparation necessary before insulin injection? Lancet. 1978;8073(1): 1072-3.

47. Frid AH, Kreugel G, Grassi G, et al. New insulin delivery recommendations. Mayo Clin Proc. 2016;91(9):1231-55.

48. Giving an insulin injection. Available at https:// medlineplus.gov/ency/patientinstructions/000660. htm. Accessed 23 Jan 2018.

49. How to inject insulin. Available at https://www. diabetes.co.uk/insulin/how-to-inject-insulin.html. Accessed 20 Jan 2018.

50. Birkebaek NH, Solvig J, Hansen B, Jorgensen C, Smedeganard J, Christiansen JS. A 4-mm needle reduces the risk of intramuscular injections without increasing backflow to skin surface in lean diabetic children and adults. Diabetes Care. 2008;31(9): e65-e65. https://doi.org/10.2337/dc2308-0977.

51. Lo Presti D, Ingegnosi C, Strauss K. Skin and subcutaneous thickness at injecting sites in children with diabetes: ultrasound findings and recommendations for giving injection. Pediatr Diabetes. 2012;13(7):525-33.

52. Naughten E, Smith MA, Baum JD. At what age do diabetic children give their own injections? Am J Dis Child. 1982;136(8):690-2. 
53. Injecting insulin and children. Available at https:// www.diabetes.org.uk/guide-to-diabetes/your-childand-diabetes/insulin-and-your-child. Accessed 20 Jan 2018.

54. Siminerio L, Kulkarni K, Meece J, et al. Strategies for insulin injection therapy in diabetes self-management bleeding and bruising. Madison: American Association of Diabetes Educators; 2011.

55. Kruger DF, LaRue S, Estepa P. Recognition of and steps to mitigate anxiety and fear of pain in injectable diabetes treatment. Diabetes Metab Syndr Obes. 2015;16(8):49-56.

56. Schober E, Wagner G, Berger G, et al. Prevalence of intentional under- and overdosing of insulin in children and adolescents with type 1 diabetes. Pediatr Diabetes. 2011;12(7):627-31.

57. Davis EM, Foral PA, Dull RB, Smith AN. Review of insulin therapy and pen use in hospitalized patients. Hosp Pharm. 2013;48(5):396-405. https:// doi.org/10.1310/hpj4805-396.

58. Safe use of insulin in primary care: collaborative baseline audit of insulin administration and documentation by community nurse teams. East \& South East England Specialist Pharmacy Services. East of England, London, South Central \& South East Coast.
59. Atun R, Davies JI, Gale EAM, Bärnighausen T, Beran D, Kengne AP, Levitt NS, Mangugu FW, Nyirenda MJ, Ogle GD et al: Diabetes in sub-Saharan Africa: from clinical care to health policy. Lancet Diabetes Endocrinol. 2017. http://doi.org/10.1016/S22138587(17)30181-X.

60. Peck R, Mghamba J, Vanobberghen F, Kavishe B, Rugarabamu V, Smeeth L, Hayes R, Grosskurth H, Kapiga S. Preparedness of Tanzanian health facilities for outpatient primary care of hypertension and diabetes: a cross-sectional survey. Lancet Glob Health. 2014;2(5):e285-92.

61. Katende D, Mutungi G, Baisley K, Biraro S, Ikoona E, Peck R, Smeeth L, Hayes R, Munderi P, Grosskurth $\mathrm{H}$. Readiness of Ugandan health services for the management of outpatients with chronic diseases. Trop Med Int Health. 2015;20(10):1385-95.

62. Huffman MD, Rao KD, Pichon-Riviere A, Zhao D, Harikrishnan S, Ramaiya K, Ajay VS, Goenka S, Calcagno JI, Caporale JE et al. A cross-sectional study of the microeconomic impact of cardiovascular disease hospitalization in four low- and middle-income countries. PLoS One. 2011;6(6):e20821. http://doi.org/10.21371/journal.pone.0020821. 